\title{
Characteristics and Application Analysis of Chinese Medicinal Herbs Containing Dates
}

\author{
Ming Bai, Xin Lou, Yanyan Miao, Mingsan Miao* \\ Henan University of Traditional Chinese Medicine \\ Zhengzhou, China
}

\begin{abstract}
Jujube also known as red dates, dried jujube, it is the dried fruit of Rhamnaceae plants. It's commonly used in clinical tranquilizing by nourishing the heart, tonifying Qi and blood, strengthening the spleen and stomach. In all ages, Chinese jujube is widely used in Clinical Prescriptions. In particular, more use is recorded in the treatise on Febrile Diseases. With the development of clinical practice for thousands of years, the trend of Chinese herbal medicine made into proprietary Chinese medicine is becoming more and more obvious. The emergence of proprietary Chinese medicine has greatly promoted the development of Chinese Medicine. At the same time, it also promoted the rapid development of the motherland's economy. While we are enjoying the convenience and economy brought by Chinese patent medicines, we should also consider the adverse effects, rational thinking and correct treatment.
\end{abstract}

Keyword: Jujube; proprietary Chinese medicine; Chinese medicine compound;

\section{OVERVIEW OF JUJUBE:}

Jujube also known as red dates, dried jujube, it is the dried fruit of Rhamnaceae plants. In autumn, ripe fruit is harvested and dried. Warm in nature, sweet, it is a common good medicine to tonifying middle-Jiao and Qi, nourishing the blood and tranquilization, nourishing liver and kidney. Modern research shows that jujube is rich in protein, sugar and other essential nutrients, and carotene, vitamins and calcium, phosphorus, iron and other trace elements and adenosine monophosphate and other nutrients. It has the functions of regulating immunity, resisting tumor, antioxidation, repairing liver injury and resisting fatigue. It also improves hematopoiesis, bowel movement, and so on. Cyclophosphamide contained in jujube is the essential component of energy metabolism in human cells, it can relieve fatigue, dilate blood vessel and improve myocardial nutrition, it has a good effect on the prevention and treatment of cardiovascular diseases; China is the most abundant country of jujube resources. It has been planted for more than 3000 years, there are 704 varieties of jujube, as the saying goes "eating three daily, never grow old".

According to statistics, in the 2015 edition of the Pharmacopoeia of People's Republic of China, there are 371 kinds of prepared and single preparations. Among them, there are 59 kinds of preparations containing jujube, about 1/6. Some of them such as Renshenyangrong pills and Buzhongyiqi pills, they are using jujube Decoction flooding pill. It is to use jujube in subsidiary material. In Han Dynasty, Doctors use jujubes to focus on Regulating Qi and Wei, invigorating spleen and promoting fluid production, and easing the effect of drug resistance. The Tang and Song Dynasties, there is more to date named has focused on the efficacyy of reinforce the spleen to benefit the lung. Jin, Yuan, Ming and Qing Dynasties. The application range decreased, and doctors focuse on tonifying middle-Jiao and Qi.

\section{CHARACTERISTICS AND APPLICATION ANALYSIS OF CHINESE PATENT MEDICINES CONTAINING JUJUBE:}

Jujube has a long history of application. it has been widely used in clinical medical, treatment of various diseases. As medicinal jujube was first seen in < Shennong bencaojing>, it has such a description of the jujube: "neutral nature, the main confidant evil, raise spleen. It helps the twelve classics, flat stomach, communicating with the nine orifices, fill one's spleen with Qi deficiency, lack of surprise in the body, heaviness of limbs. It can ease the drug properties of a variety of drugs". It is listed as the top grade. In the Han Dynasty, Zhang Zhongjing applies jujube in great quantities to mix with other medicines, and the prescription is used to cure the disease in <ShangHanLun>, among them, 113 cases of clinical compound, there are 58 cases of use of jujube, it have notable and remarkable efficiency. Chinese patent drug is the essence of clinical treatment of TCM for thousands of years, more convenient Chinese medicine prescription in clinical application. It also promotes the development of traditional Chinese medicine and traditional Chinese Medicine.

Present mainly from the following four aspects to introduce the application of jujube proprietary Chinese medicine:

The main effect of jujube is tonifying spleen and stomach, nourishing qi and blood. <Golden medicine slightly> records: 100 Chinese dates made into yam pills, the treatment of "deficiency of labour and the deficiency of Qi and the hundred kinds of phlegm". There are 21 kinds of prescription and traditional Chinese Medicine, the amount of jujube is the most. Song dynasty < Taiping Huimin Heji Ju Fang > records: zao rou ping wei san treat Spleen and stomach disharmony, do not feel like eating and distention and distension of the abdomen and the bitter taste and shortness of breath vomit dirty, and so on. The characteristics of jujube with warm, the centralizer cure. Doctor Zhang Xichun uses jujube, ginger, Atractylodes, and Gallus gallus combination to make benefit spleen cake to treatment of spleen dampness and eat less loose stool. It also takes jujube benefit spleen and stomach, make up the 
work of Qi. Chinese date compatibility with licorice, wheat (Ganmai dazao decoction) can treat woman hysteria (Depression), the jujube of fangzhongzao has the function of sweet and smooth and slow. Jujube and prepared rhizome of Angelica sinensis and donkey hide gelatin are used together to cure blood deficiency syndrome. The compatibility of Euphorbia kansui root, jujube, etc. ten jujube decoction is Daphne Zhang Zhongjing created by Purgating, for drinking water. The gansui, euphorbia and daphne flowers of the fang are the poisonous medicine to break the drinking water, strong in nature, easy to hurt Qi, and it is combined with jujube, Quxie injury is the protection of stomach qi.

TABLE I. JUJUBE IS KING'S MEDICINE

\begin{tabular}{|c|c|c|}
\hline Medicine & Dosage & Characteristic \\
\hline $\begin{array}{l}\text { Ginger jujube cold } \\
\text { dispelling granule }\end{array}$ & $310 \mathrm{~g}$ & $\begin{array}{l}\text { dispelling heat to dispel cold,and the } \\
\text { temperature in the stomach }\end{array}$ \\
\hline Fukeshiwei Tablets & $100 \mathrm{~g}$ & $\begin{array}{l}\text { raise the liver blood,regulate the } \\
\text { channels and relieve pain }\end{array}$ \\
\hline Fuketiaojing tablets & $80 \mathrm{~g}$ & $\begin{array}{l}\text { nourishing blood and liver, Qi regulate } \\
\text { the menstrual function }\end{array}$ \\
\hline Yangxue Tiaojing pill & $80 \mathrm{~g}$ & $\begin{array}{l}\text { enrich the blood, regulate the flow of } \\
\text { vital energy and remove obstruction } \\
\text { toit, regulate menstruation }\end{array}$ \\
\hline $\begin{array}{l}\text { Jujube pellets } \\
\text { (granule) }\end{array}$ & $150 \mathrm{~g}$ & $\begin{array}{l}\text { replenish qi and enrich the blood, } \\
\text { strengthening the spleen and stomach }\end{array}$ \\
\hline Xinxuebao capsule & - & $\begin{array}{l}\text { invigorate the blood and invigorate the } \\
\text { spleen and stomach }\end{array}$ \\
\hline $\begin{array}{l}\text { Donkey hide gelatin } \\
\text { triple cream }\end{array}$ & $300 \mathrm{~g}$ & $\begin{array}{l}\text { benefit qi and blood, strengthening the } \\
\text { spleen and stomach }\end{array}$ \\
\hline $\begin{array}{l}\text { Yangxin Dingji oral } \\
\text { liquid (cream) }\end{array}$ & $200 \mathrm{~g}$ & $\begin{array}{l}\text { nourishing qi and blood, Fumaiding } \\
\text { palpitated }\end{array}$ \\
\hline Yiqi weixue granules & $100 \mathrm{~g}$ & tonifying Qi and blood \\
\hline $\begin{array}{l}\text { Supplementary } \\
\text { beneficial gas } \\
\text { particles }\end{array}$ & $110 \mathrm{~g}$ & $\begin{array}{l}\text { tonify middle-Jiao and Qi, ascending up } \\
\text { spleen-qi and yang }\end{array}$ \\
\hline Jujube ginseng pills & 10 & tonifying qi \\
\hline Platycladi seed pill & $300 \mathrm{~g}$ & Nourishing blood to nourish yin \\
\hline $\begin{array}{l}\text { Compound Zaofan } \\
\text { Pills }\end{array}$ & - & $\begin{array}{l}\text { The kidney and the healthy marrow, } \\
\text { tonifying qi and yin, hemostasis by } \\
\text { blood stasis }\end{array}$ \\
\hline $\begin{array}{c}\text { Sweat stopping } \\
\text { particle }\end{array}$ & $500 \mathrm{~g}$ & $\begin{array}{l}\text { tonifying qi and yin, consolidating the } \\
\text { exterior and arresting perspiration }\end{array}$ \\
\hline
\end{tabular}

Chinese jujube as a supplement has two meanings. First, it is to reinforce the prescription to strengthen the treatment of the main disease or the main syndrome. The second is for the treatment of both disease and syndrome. Take Jianpi Sheng Xue tablet as an example, its main function is to strengthen the spleen and stomach, nourish the blood and tranquilization. Its main component is Codonopsis pilosula, Poria cocos, roasted Rhizoma Atractylodis Macrocephalae, liquorice, Astragalus mongholicus, Chinese yam, Fried chicken gizzard, Vinegar turtle, Radix Liriopes, kadsura longepedunculata, fossil fragments, calcined oyster shell, copperas, Chinese-date. Jujube nourishing blood and tranquilizing the mind are important medicines.

Some prescriptions use jujube to alleviate the strong and strong drug resistance, educe the side effect, it means jujube and "undred pills". Qingre Yinhua syrup main ingredients have Lonicera confusa DC. 100g, rhizoma imperatae $100 \mathrm{~g}$, green tea leaf $8 \mathrm{~g}$, chrysanthemum $100 \mathrm{~g}$, ricepaper pith $20 \mathrm{~g}$, liquorice $20 \mathrm{~g}$ and jujube $50 \mathrm{~g}$. Chinese date mixing herbs. It is the adjuvant medicine. The drug combination plays Qingrejiedu, promoting urination

Application
anemofrigid cold, stomach cold pain
irregular menses,algomenorrhea, syndrome of menstruation before and
after menstruation due to liver qi depression
irregular menses, irregular menstruation, abdominal pain during
menstruation due to liver qi depression
stagnancy of qi and blood stasis, irregular menstruation, abdominal
distension, leukorrhea with reddish discharge
neutropenia, weakness after disease, poor immune system due to liver
loss
qi-blood deficiency due to hypoferric anemia

Cardiopalmus, breathe hard, low food intake, uterine bleeding, general edema due to deficiency of both Qi and blood and weakness of the spleen and the stomach

energy and blood deficiency, palpitation and shortness of breath,

irregularity of pulse, night sweats insomnia, dry throat and tongue, dry stool

pale or sallow complexion, circumgyration, fatigued spirit and lack of strength, lack of qi and no desire to speak, spontaneous perspiration, pale lips, weak pulse due to qi-blood deficiency

diarrhea, archoptoma, prolapse of the uterus due to weakness of the spleen and the stomach and sinking of qi of middle-jiao

\section{deficiency of qi and blood}

Deficiency of yin and blood weakness, pain in my hands and feet, gradually emaciation, pulse micro number

aplastic anemia, leuco(cyto) penia, thrombocytopenia, myelodysplastic syndrome

Spontaneous sweating, night sweats and night sweats in children due to insufficiency of Qi and Yin

function. This is the jujube and medicine, the king of cold and official medicine Yaoshan honeysuckle chrysanthemum taste Xin Jun strong of ease, to reconcile the main drugs, reduce side effects.

Jujube as adjunct, first, the meridian medicine, that is, the medicine which can induce the medicine in the square to reach the focus. The second is the mixture medicine, that is, a drug that coordinates the action of various drugs. The drug is small. Add a few more dates in Chinese medicine. This is the "clue". If there is no match, the effect of Chinese medicine is sometimes hard to guarantee. Take Anshen Anshen tablet as an example, it is used inpanasthenia, headache, dizziness and forgetfulness insomnia due to insufficiency of the kidney yang and deficiency of kidney-essence. Huang Jing, tonifying kidney, tonifying essence, it is king's medicine, pilose deer horn, Antler Glue, gelatinum cornus cervis, Aceranthus sagittatus S. et $Z$. as remedy, they are warming kidney and activating yang. Jujube as adjuvant, and it has supplementing qi and tonifying the stomach to nourish the blood and soothe the nerves effects. 
TABLE II. JUJUBE IS THE OFFICIAL MEDICINE

\begin{tabular}{|c|c|c|c|}
\hline Medicine & Dosage & Characteristic & Application \\
\hline $\begin{array}{l}\text { Ascending blood } \\
\text { granule }\end{array}$ & - & benefiting qi and nourishing blood & $\begin{array}{l}\text { pale white complexion, vertigo, cardiopalmus, fatigued spirit and lack } \\
\text { of strength, breathe hard due to qi-blood deficiency }\end{array}$ \\
\hline $\begin{array}{l}\text { Jianpi Sheng Xue } \\
\text { tablet }\end{array}$ & - & $\begin{array}{l}\text { strengthening the spleen and stomach, } \\
\text { nourishing the blood and tranquilization }\end{array}$ & $\begin{array}{c}\text { deficiency of blood due to weakness of the spleen and the stomach and } \\
\text { insufficiency of heart and spleen }\end{array}$ \\
\hline $\begin{array}{l}\text { Yi Xue Sheng } \\
\text { capsule }\end{array}$ & $14 \mathrm{~g}$ & $\begin{array}{l}\text { Invigorate the spleen and kidney, blood } \\
\text { engendering essence }\end{array}$ & $\begin{array}{c}\text { lusterless complexion, dizziness and shortness of breath, fatigued body } \\
\text { and lack of strength, soreness and weakness of waist and knees due to } \\
\text { asthenia of both the spleen and kidney and asthenia of essence and } \\
\text { blood }\end{array}$ \\
\hline $\begin{array}{l}\text { Ginseng Bolus for } \\
\text { Tonification }\end{array}$ & $100 \mathrm{~g}$ & $\begin{array}{l}\text { Warming Qi and supplementing qi and } \\
\text { blood }\end{array}$ & $\begin{array}{c}\text { deficiency of both the heart and spleen, deficiency of both QI and } \\
\text { blood, vacuity following illness }\end{array}$ \\
\hline $\begin{array}{l}\text { Tonic and } \\
\text { invigorated water } \\
\text { pills }\end{array}$ & $40 \mathrm{~g}$ & the same as the beneficial gas particles & the same as the beneficial gas particles \\
\hline $\begin{array}{l}\text { Tonic and } \\
\text { invigorated } \\
\text { mixture }\end{array}$ & $56 \mathrm{~g}$ & the same as the beneficial gas particles & the same as the beneficial gas particles \\
\hline Zhigancao mixture & $118 \mathrm{~g}$ & $\begin{array}{l}\text { benefiting qi and nourishing yin, clearing } \\
\text { Yin to restore pulse }\end{array}$ & energy and blood deficiency, severe palpilation, intermittent pulse \\
\hline $\begin{array}{l}\text { Xiao Chaihu } \\
\text { effervescent } \\
\text { tablets }\end{array}$ & $575 \mathrm{~g}$ & $\begin{array}{l}\text { Relieving heat dissipation, dispersing } \\
\text { stagnated liver qi for regulating stomach }\end{array}$ & externally contracted disease, evil Shaoyang syndrome \\
\hline $\begin{array}{l}\text { Xiaocaihu tablets } \\
\text { (capsules) }\end{array}$ & $167 \mathrm{~g}$ & the same as above & the same as above \\
\hline $\begin{array}{l}\text { Bezoar sedative } \\
\text { pills }\end{array}$ & - & $\begin{array}{l}\text { Clearing away phlegm, dispelling } \\
\text { pathogenic wind to dispel pathogenic wind }\end{array}$ & $\begin{array}{l}\text { Dizzy,barylalia, epilepsia, convulsion due to obstruction of orifices } \\
\text { caused by wind-phlegm }\end{array}$ \\
\hline $\begin{array}{l}\text { Jieyu Anshen } \\
\text { granule }\end{array}$ & $40 \mathrm{~g}$ & $\begin{array}{c}\text { dispersing stagnated liver qi for relieving qi } \\
\text { stagnation }\end{array}$ & $\begin{array}{c}\text { lose sleep, vexation, anxious, forgetful due to gloomy mood and } \\
\text { stagnation of liver Qi }\end{array}$ \\
\hline $\begin{array}{l}\text { Anshenbunao } \\
\text { liquid (tablet) }\end{array}$ & - & $\begin{array}{l}\text { tranquilizing the mind, supplementing } \\
\text { essence and supplementing marrow, } \\
\text { reinforce qi and nourishing blood }\end{array}$ & $\begin{array}{l}\text { lose sleep, forgetful, dizzy and lacking in strength due to deficiency of } \\
\text { kidney-essence, deficiency of both QI and blood }\end{array}$ \\
\hline Guizhi mixture & - & relieving muscles diaphoresis & have a headache and fever, nasal retching, sweating evil wind \\
\hline $\begin{array}{l}\text { Gegen Decoction } \\
\text { tablet (granule) }\end{array}$ & $1222 \mathrm{~g}$ & $\begin{array}{c}\text { inducing sweat and dispelling exogenous } \\
\text { evils, }\end{array}$ & wind-cold type of common cold \\
\hline
\end{tabular}

\section{TABLE III. JUJUBE AS ADJUVANT}

\begin{tabular}{|c|c|c|c|}
\hline Medicine & Dosage & Characteristic & Application \\
\hline Erkangning syrup & - & strengthen the spleen and replenishing qi & Apositia due to deficiency of spleen-QI and stomach-QI \\
\hline Zhuanggu Granule & - & $\begin{array}{l}\text { warm stomach and invigorate spleen, } \\
\text { trengthening tendons and bones }\end{array}$ & $\begin{array}{c}\text { Treatment and Prevention rickets, Children with } \\
\text { hyperhidrosis }\end{array}$ \\
\hline $\begin{array}{l}\text { Guipi pill } \\
\text { (concentrated pill) }\end{array}$ & $40 \mathrm{~g}$ & $\begin{array}{l}\text { replenishing qi to invigorate the spleen, } \\
\text { nourishing the blood and tranquilization }\end{array}$ & $\begin{array}{c}\text { insufficiency of heart and spleen, shortness of breath and } \\
\text { palpitation }\end{array}$ \\
\hline Guipi granule & $70 \mathrm{~g}$ & As with Guipi pills & As with Guipi pills \\
\hline Xiaojianzhong tablet & $1110 \mathrm{~g}$ & $\begin{array}{l}\text { warming middle-Jiao and tonifying } \\
\text { deficiency, relieving spasm and pain }\end{array}$ & $\begin{array}{l}\text { deficiency-cold in spleen and stomach, pain in the stomach } \\
\text { duct and abdomen }\end{array}$ \\
\hline $\begin{array}{l}\text { Xiaojianzhong } \\
\text { granules }\end{array}$ & $200 \mathrm{~g}$ & As with Xiaojianzhong tablet & As with Xiaojianzhong tablet \\
\hline Xiaoshi spleen pill & $50 \mathrm{~g}$ & tonifying spleen, relieving dyspepsia & $\begin{array}{l}\text { abdominal fullness and distention, anorexia, emaciation with } \\
\text { sallow complexion }\end{array}$ \\
\hline $\begin{array}{l}\text { Huangqi Jianwei } \\
\text { ointment }\end{array}$ & $122 \mathrm{~g}$ & Air temperature, relieving spasm and pain & $\begin{array}{l}\text { Stomachache caused by deficiency of the spleen and } \\
\text { stomach }\end{array}$ \\
\hline Qingre Yinhua syrup & $50 \mathrm{~g}$ & $\begin{array}{c}\text { clearing away heat and toxic material, free } \\
\text { urine }\end{array}$ & $\begin{array}{c}\text { head heavy as if swathed, difficulty in micturition due to } \\
\text { exogenous summer heat dampness }\end{array}$ \\
\hline $\begin{array}{l}\text { Shaoyang cold } \\
\text { particles }\end{array}$ & $138 \mathrm{~g}$ & $\begin{array}{l}\text { relieving heat dissipation, relieving } \\
\text { shaoyang disorder }\end{array}$ & Exopathogens made Shaoyang syndrome. \\
\hline
\end{tabular}

\section{EXPECTATION}

From the statistics above, there are nearly 22 kinds of Chinese patent medicine preparations in tonifying Qi and blood, in the spleen and stomach is about 20 kinds, there are about 14 kinds in nourishing heart and calm the nerves, It also has many proprietary Chinese medicine preparations in the aspects of nourishing the lung, regulating qi and relieving the exterior, which are available for the patients to choose. As it can be seen from the general classification above, Jujube plays an important role in the main aspects, such as Nourishing qi and blood, calming the nerves, recuperating the spleen and stomach and so on. Compatibility with other drugs also has different effects, It does not mean that it can be divided into only one category, For example, Yi xue sheng capsule, not only it has the effect of invigorating the spleen and kidney, but also the effect of producing blood and filling essence, in traditional Chinese Medicine, the spleen is the foundation of acquired, it is the source of Qi and blood biochemistry, it is mainly used in the pathogenesis of insufficient blood gas due to asthenia of both the spleen and kidney. Donkey hide gelatin nourishing yin, nourishing blood, donkey hide gelatin triple cream applied 
in compatibility with Chinese dates, it give full play to the role of blood.

TCM has long been treated with jujube, The earliest pharmaceutical classics < Sheng Nong's herbal classic> as top grade in China, From Zhang Zhongjing, Sun Simiao to the Chinese medicine pharmacists all cannot do without jujube to treat disease. In the modern fast-paced, stressful life, many people have anxiety, insomnia and a series of problems, and jujube as our daily food, you can eat more, play its value. And now there are a lot of literature research to systematically analyze the nutritional ingredients, kinds and content of jujube, there are also many health food products available on the market. At the same time, Chinese jujube not only has the advantages of rich resources, but also has advantages in cultivation, make full use of these advantages, give full play to the potential value of jujube, alleviate pain for clinical patients and contribute to the country's economic growth.

TABLE IV. JUJUBE IS USED AS MEDICINE

\begin{tabular}{|c|c|c|c|}
\hline Medicine & Dosage & Characteristic & Application \\
\hline shenling baizhu powder & - & $\begin{array}{l}\text { tonifying spleen and stomach, } \\
\text { invigorate qi }\end{array}$ & $\begin{array}{c}\text { weakness of the spleen and the stomach, eat less loose stools, } \\
\text { shortness of breath and cough }\end{array}$ \\
\hline Flat stomach pill & $4 \mathrm{~g}$ & $\begin{array}{l}\text { dry dampness and strengthening } \\
\text { the spleen, loosen the chest and } \\
\text { disperse distention }\end{array}$ & $\begin{array}{c}\text { Dampness of the spleen and stomach, poor appetite, } \\
\text { abdominal fullness and distention, nausea and vomiting, } \\
\text { Belching Tunsuan }\end{array}$ \\
\hline $\begin{array}{l}\text { The curative effect of six } \\
\text { Jun tablets }\end{array}$ & $20 \mathrm{~g}$ & $\begin{array}{l}\text { Replenishing qi to invigorate the } \\
\text { spleen, harmonize the stomach }\end{array}$ & $\begin{array}{l}\text { Stagnation of Spleen Qi, indigestion, eructation and poor } \\
\text { appetite, abdominal fullness and distention }\end{array}$ \\
\hline $\begin{array}{l}\text { Virtual cold stomachache } \\
\text { granules }\end{array}$ & - & $\begin{array}{l}\text { replenish qi to invigorate the } \\
\text { spleen,warm stomach to relieve } \\
\text { pain }\end{array}$ & Stomach pain due to spleen asthenia and stomach weakness \\
\hline xiangsha yangwei pills & $150 \mathrm{~g}$ & $\begin{array}{l}\text { warm the middleto harmonize } \\
\text { thesto }\end{array}$ & Stomachache, distention and fullness \\
\hline $\begin{array}{l}\text { Ginger heart clearing } \\
\text { tablet }\end{array}$ & $120 \mathrm{~g}$ & And the new by the stomach & disorder of the stomach, epigastric fullness \\
\hline Gastrointestinal Ann pill & - & $\begin{array}{l}\text { stagnation of stomach qi, } \\
\text { regulating qi to alleviate pain }\end{array}$ & $\begin{array}{l}\text { diarrhea, loss of appetite, sicchasia, vomit, abdominal } \\
\text { distension, abdominal pain due to food stagnation }\end{array}$ \\
\hline Weiyangling Granules & $166.7 \mathrm{~g}$ & $\begin{array}{l}\text { The temperature of yiqi, relieving } \\
\text { spasm and pain }\end{array}$ & $\begin{array}{l}\text { Stomachache due to deficient cold of spleen and stomach, } \\
\text { deficiency of qi in middle-jiao }\end{array}$ \\
\hline Table virtual cold particles & - & $\begin{array}{l}\text { The wind scattered solution } \\
\text { muscle, }\end{array}$ & Cold and wind cold syndrome \\
\hline $\begin{array}{l}\text { Modified Huoxiang } \\
\text { Zhengqi Soft Capsule }\end{array}$ & - & $\begin{array}{l}\text { Resolve exterior dampness, } \\
\text { regulate vital energy and a middle } \\
\text { warmer }\end{array}$ & $\begin{array}{c}\text { affection of exotenous wind-cold, damp stagnation of internal } \\
\text { injury }\end{array}$ \\
\hline Jiannao Anshen tablet & $16 \mathrm{~g}$ & $\begin{array}{l}\text { nourishe and tonic effects, } \\
\text { tranquilize and allay excitement }\end{array}$ & Panasthenia, headache, dizzy, forgetfulness insomnia, tinnitus \\
\hline Sishen Wan (tablets) & $189 \mathrm{~g}$ & $\begin{array}{l}\text { Reinforcing kidney to dissipate } \\
\text { cold,elimination of diarrhoea bulge }\end{array}$ & $\begin{array}{l}\text { Kidney deficiency and cold, borborygmus abdominal } \\
\text { swelling, food poisoning, chromic diarrhea, pale and weak }\end{array}$ \\
\hline Qingyu pi wen dan & $40 \mathrm{~g}$ & monarch arebad, vomiting diarrhea & experience summer heat evil, dizziness and chest distress \\
\hline Guishao Zhenxian tablets & $296 \mathrm{~g}$ & Clear liver and gallbladder & Various types of seizures \\
\hline
\end{tabular}

\section{ACKNOWLEDGEMENTS}

Foundation item: Henan campus Cooperation Award (The finance and education (2016)38), Henan industry university research project (172107000012), Zhengzhou university research project (Zhengkeji 2016(4)).

\section{REFERENCE}

[1] Guo Lin, Miao Ming. Three. Modern study and analysis of Chinese date [j]. Journal of Chinese medicine, 2014, (04): 543-545.

[2] Ben Liu Baoheng. Following, jujube in "Treatise on Febrile Diseases $>$ in the combined application of [j]. Asia Pacific traditional medicine, 2013, (04): 45.

[3] Peng Hao, Yao Zhen, Ling Changquan. Discussion on the application of jujube in Treatise on Febrile Diseases [j]. Chinese Journal of Chinese medicine, 2016,31 (03): 782-783. [2017-08-25].

[4] Liu Shijun, Tang Zhishu, Cui Li, Liu Hongbo, Liang Yanni, Zhang $\mathrm{Yu}$, Wang Mei. Research progress of chemical constituents of Chinese jujube [j]. Journal of Yunnan University of Traditional Chinese Medicine, 2015, (03): 96-100.

[5] Wang Zheng, Zhou Yongxue. Analysis of the combination rules of ginger, Chinese date and licorice in $<<$ treatise on Febrile Diseases > > [j]. modern Chinese medicine, 2016, (03): 77-79.

[6] Yang Wenchao. Analysis of compatibility of Chinese and Chinese dates in Poria and cinnamon date Decoction [j]. Shaanxi traditional Chinese medicine, 2015, (10): 1426-1427.
[7] Xin Jiliang. Image number thinking in the application of Chinese jujube in Treatise on Febrile Diseases [j]. National Medical Forum, 2017,32 (01): 5-6. [2017-08-25].

[8] Wang Zheng, Zhou Yongxue. Analysis of decoction for reducing and restoring pulse, going to Chinese jujube, [j]., Henan traditional Chinese medicine, 2016, (09): 1491-1493.

[9] Wang Zheng, Zhou Yongxue. Analysis of the combination rules of ginger, Chinese date and licorice in $<<$ treatise on Febrile Diseases > > [j]. modern Chinese medicine, 2016, (03): 77-79.

[10] Zhou Wen. < < Qianjin Zi, Fang > >. Study on the application rule of ginger, date and licorice. [d]. Chengdu University of Traditional Chinese Medicine, 2014.

[11] Li Hongbin, Li Renshu. Listed on the Chinese medicine review and Reflection on the re evaluation system of Chinese herbal medicine [j]., 2015, (02): 293-296.

[12] Xu Fangqin Zhang Xinrui, Guo Fengwei, Xiang Rong, and the East, Tian. Progress of Chinese traditional medicine quality control of modern biomedical research progress of [j]. 2014 (31): 6159-6163.

[13] Cao Xiao, Yu, Yu Shui, Wang Xuliang, Niu Chun Feng. Zhang Zhongjing's use of Chinese dates. A brief comment on [j]. Journal of Changchun University of Traditional Chinese Medicine, 2017,33 (03): 499-501. [2017-08-25].

[14] Zheng Qin, Wei Shaofeng, Xue Xin, Xiong Wen Hai, Wu Zhenfeng, Li Yingmeng, Yu Jin, Yang Ming. Application of [j]. in Chinese herbal medicine Chuanxiong prescription analysis in Chinese medicine for treatment of headache, 2013 (19): 2777-2781. 